\title{
Article \\ Application of a High-Precision Aeolian Sand Collector in Field Wind and Sand Surveys
}

\author{
Xinchun Liu ${ }^{1}{ }^{\circ}$, Yongde Kang $2, * \mathbb{C}$, Hongna Chen ${ }^{3}$ and Hui Lu ${ }^{4,5}$ \\ 1 Institute of Desert Meteorology, CMA, Taklimakan Desert Meteorology Field Experiment Station of CMA, \\ Xinjiang Laboratory of Tree Ring Ecology, Key Laboratory of Tree-Ring Physical and Chemical Research of \\ China Meteorological Administration, Urumqi 830002, China; liuxch@idm.cn \\ 2 State Key Laboratory of Eco-Hydraulics in Northwest Arid Region of China, School of Water Resources and \\ Hydroelectric Engineering, Xi'an University of Technology, Xi'an 710048, China \\ 3 Urumqi Environmental Monitoring Center, Urumqi 830001, China; liuxinchun2001@163.com \\ 4 Key Laboratory of Ecology of Rare and Endangered Species and Environmental Protection, Guangxi Normal \\ University, Ministry of Education, Guilin 541004, China; luhui1008@163.com \\ 5 College of Environment and Resources, Guangxi Normal University, Guilin 541004, China \\ * Correspondence: kyd0115@yeah.net; Tel.: +86-199-4623-5190
}

Citation: Liu, X.; Kang, Y.; Chen, H.;

$\mathrm{Lu}, \mathrm{H}$. Application of a

High-Precision Aeolian Sand Collector in Field Wind and Sand Surveys. Int. J. Environ. Res. Public Health 2021, 18, 7393. https:// doi.org/10.3390/ijerph18147393

Academic Editor: Alan W. Gertler

Received: 17 June 2021

Accepted: 5 July 2021

Published: 10 July 2021

Publisher's Note: MDPI stays neutral with regard to jurisdictional claims in published maps and institutional affiliations.

Copyright: (c) 2021 by the authors. Licensee MDPI, Basel, Switzerland. This article is an open access article distributed under the terms and conditions of the Creative Commons Attribution (CC BY) license (https:/ / creativecommons.org/licenses/by/ $4.0 /)$.

\begin{abstract}
Sand collectors are important for quantitatively monitoring aeolian sand activities. In this paper, an automatic high-precision sand collector was designed. Based on the measured data of aeolian transport performed with a piezoelectric saltation sensor (H11-Sensit) and a $10 \mathrm{~m}$ high meteorological tower, the sampling efficiency of the automatic sand sampler and the horizontal dust flux of the near surface were analyzed based on observed data. The results were as follows: the bestfitting function between the number of impacting sand particles and the amount of collected sand was a linear relationship. The average value of $R^{2}$ was 0.7702 , and the average sand collection efficiency of the sand collector at a height of $5 \mathrm{~cm}$ was $94.3 \%$, indicating good sand collection performance. From all field tests conducted so far, it appeared that a high-precision sand sampler was a useful device for making field measurements of horizontal dust fluxes and ascertaining the relationship between transition particles and wind speed. In the future, the equipment costs and wind drive will continue to be optimized.
\end{abstract}

Keywords: soil erosion; wind erosion; sand collection efficiency; dust horizontal flux

\section{Introduction}

Wind is an important erosion force that shapes the surfaces of Earth, Venus, Mars, and Titan [1,2]. In arid, semi-arid, high latitude, and high-altitude regions on Earth, wind erosion is usually considered to be the main driving force for soil loss and dust release [3-6]. Quantitative studies of wind-induced sand migration have played an important role in revealing the geomorphological processes, and soil losses and wind erosion dust have been accurately simulated [7-9]. In some countries, the annual average particulate matter (e.g., PM2.5 and PM10) mass concentrations are high [10], where the major emission sources of PM are the degradation of soil and the mismanagement of lands [10].

Many studies have been carried out on horizontal sand dust fluxes, such as in Europe, China, Canada, Australia, and the United States, especially in arid and semi-arid regions. On Earth, this occurs mainly in deserts, on beaches, and in other sparsely vegetated areas, such as dry lake beds [11-15]. The lift-off velocities of differently sized particles obey different distribution functions. The mean particle velocity at different heights also depends on momentum exchange and particle concentration.

Because of the difficulty of obtaining relevant measurements, integrated dust samplers have historically been the most common method for measuring sand dust fluxes in the field and in laboratory investigations [16-18]. Different researchers have designed various types 
of sand samplers [19-22] to study the horizontal and vertical fluxes of dust transport in the near strata [23-35], and they are widely used to obtain sand transport measurements in field and in wind tunnel experiments [36-39]. Initial designs were improved by increasing the sampling efficiency through taking account of the aerodynamics associated with blocking a portion of the flow [17]. Additional improvements were made by increasing the temporal resolution through automatic weighing systems $[40,41]$ to retroactively apply a temporal signature to the mass flux of sand dust [42]. However, the spatial and temporal resolution of a mass-collecting sand dust traps remain insufficient for capturing most small-scale aeolian processes. In addition, because sand traps obstruct aerodynamic processes to varying degrees, the efficiency of sampling sand dust is variable, and differs with height and wind conditions [43], but is generally around 80\% [44]. In short, traditional sediment collectors (such as the big spring number eight, BSNE, and modified Wilson and Cooke (MWAC) samplers) cannot automatically collect and weigh sediment flux, nor can wind erosion sensors (such as the Sensit and Wenglor laser fork).

The aim of this study was to understand the sand dust transport process and sampling efficiency more fully. Thus, our research group designed an automatic, long-period, and high-frequency sand sampler. The sand collector designed in this paper has two innovations, focused at overcoming two problems: one is the interference of the sand collector on the airflow in the measurement section and the other is the exhaust problem inside the sand collector. The inlet of the sand sampler has been designed as a wedge, and a wind speed guide groove and airflow guide outlet are also incorporated into the design. A hollow shaft was designed as a special dustproof system (i.e., with first and second air leakage networks) so that the airflow could be discharged into the atmosphere before entering the hollow shaft. Consequently, the influence of the sand collector on the airflow was minimized, which conformed to the principle of equal dynamic performance of the sand collector design, which is of great significance to improving the sand collection efficiency. Additionally, the dust collection of the sand collector realized the real-time dynamic monitoring of wind erosion by combining dynamic dust collection with static weighing. Through this multistage weighing approach, a historic breakthrough was achieved in terms of measurement accuracy and resolution, and the measurement range has been greatly improved. Thus, the high-precision, high-frequency, and long-period automatic monitoring of sand dust was truly realized, which automatically recorded at high speeds and accurately reflected any changes of the dust. In addition, the advantages of this sand collector were a low failure rate, strong maintainability, and a wide range of use. It was not only able to observe the wind and sediment activities at the height of several centimeters to several meters above the surface, but was also able to observe these at heights of zero to several hundred meters.

Field experiments were conducted using the sand sampler, existing meteorological data, and a Sensit wind erosion sensor to reveal the characteristics of the mass flux, mass concentration, horizontal velocity, and impact number of particles, thus enhancing our understanding of the characteristics and relationships of dust activities in the area. At the same time, the results from this paper provided useful input data for theoretical analyses and numerical model validation.

\section{Materials and Methods}

\subsection{Study Area}

The study area is located around a western station used to make wind drift sand flow observations in Tazhong, China $\left(83^{\circ} 39^{\prime} \mathrm{E}, 38^{\circ} 58^{\prime} \mathrm{N}\right)$, in the hinterland of the Taklimakan Desert (Figure 1). The area has a typical temperate continental climate, with high temperatures in dry summers, including little precipitation, rich sand resources, and scarce vegetation. It has an average annual temperature of $13.6{ }^{\circ} \mathrm{C}$, temperature extremes of $46.0^{\circ} \mathrm{C}$ and $-5.0{ }^{\circ} \mathrm{C}$, an average annual precipitation of only $25.9 \mathrm{~mm}$, and an average annual evaporation capacity of up to $3812.3 \mathrm{~mm}$. The area is also characterized by frequent blowing sands and sandstorms, with more than 500 annual sand windstorms $(6.0 \mathrm{~m} / \mathrm{s}$, measured at $11.4 \mathrm{~m}$ above the ground), average wind speeds of $2.5 \mathrm{~m} / \mathrm{s}$, a maximum 
instantaneous wind speed of $20.0 \mathrm{~m} / \mathrm{s}$, and a blown-sand activity index of about 8000 . The main wind directions are ENE, EN, and NNE. The frequency of sandstorms and blowing sands was high from March to August. The regional sandstorms in this area feature long durations and poor visibilities. Previous studies showed that $91 \%$ of the sand grains at a $5 \mathrm{~cm}$ height were in the range of 63-250 $\mu \mathrm{m}$, with most in the range of 125-250 $\mu \mathrm{m}[45,46]$.

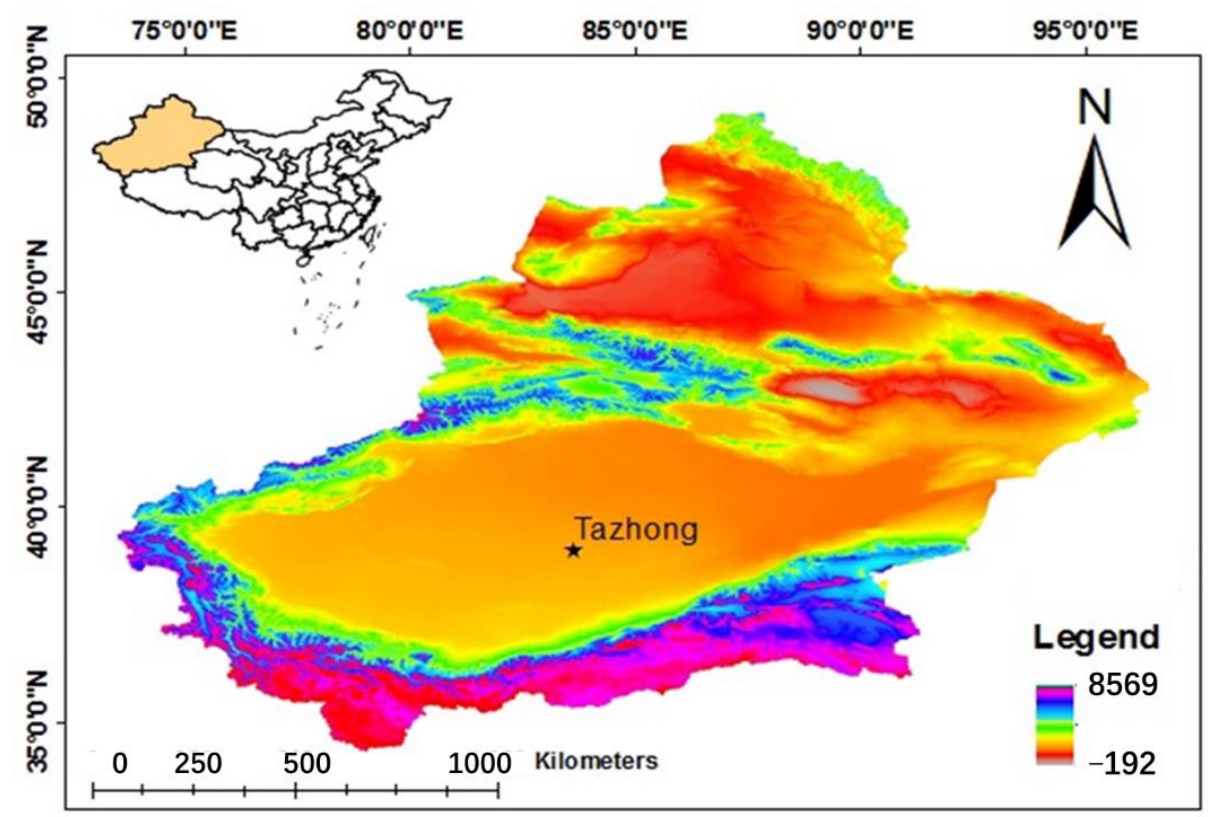

Figure 1. Map of the study area, showing the location of the Tazhong site in the Taklimakan Desert of Xinjiang Province, China.

\subsection{Construction of the Sand Collector}

The core structures of the sand sampler (Figure 2) were a dust collection system and a dust measurement system. The dust collection system was installed above the device enclosure (components 1-6 in Figure 2), which mainly consisted of an empennage, first air leakage network, second air leakage network, sand intake, hollow shaft, and bearing dust proof seat. The static measurement system was in the device enclosure, which was mainly composed of a small-range, high-precision dust weighting system and a largescale dust weighting system. The small-range, high-precision dust weighting system consisted of an automatic sand release device and a small-scale, high-precision weighing sensor. The small-scale, high-precision weighting sensor was mounted on the inner wall of the device enclosure, and the automatic sand release tipping bucket was related to the small-scale, high-precision weighting sensor. The automatic sand release device consisted of a small-capacity container (tipping bucket) and a container support shaft. The small capacity container and container support shaft were related to a flexible rod, which can rotate around the support shaft. The large-scale dust weighting system consisted of a large capacity container and a large-scale weighting sensor. The large capacity container was mounted on the second platform. One end of the large-scale weighting sensor was fixed under the second platform and the other end was fixed on the inner wall of the device enclosure. Conveniently, the large-capacity container was designed as an inverted truncated cone-shaped container, which could help concentrate the center of the gravity of the collected objects to the sensing part of the weighting sensor.

To improve the measurement accuracy and range of the sand sampler, graded weighting was adopted. The range of the first-grade weighting container was 0-300 $\mathrm{g}$ with an accuracy of $20 \mathrm{mg}$, and the range of the second-grade weighting container was $0-10 \mathrm{~kg}$. Sampling was carried out with the created device for twelve months at the test site, and automatic observations were realized, where an aspect sensor was used to monitor the sand amounts arising from each direction. The data acquisition system had a high storage 
capacity (2 GB) and high frequency $(\geq 1 \mathrm{~Hz})$, which allowed us to dynamically and comprehensively record the processes and dynamic variations of dust emission arising from wind erosion in real time and weigh the collected dust with high precision over a wide range.

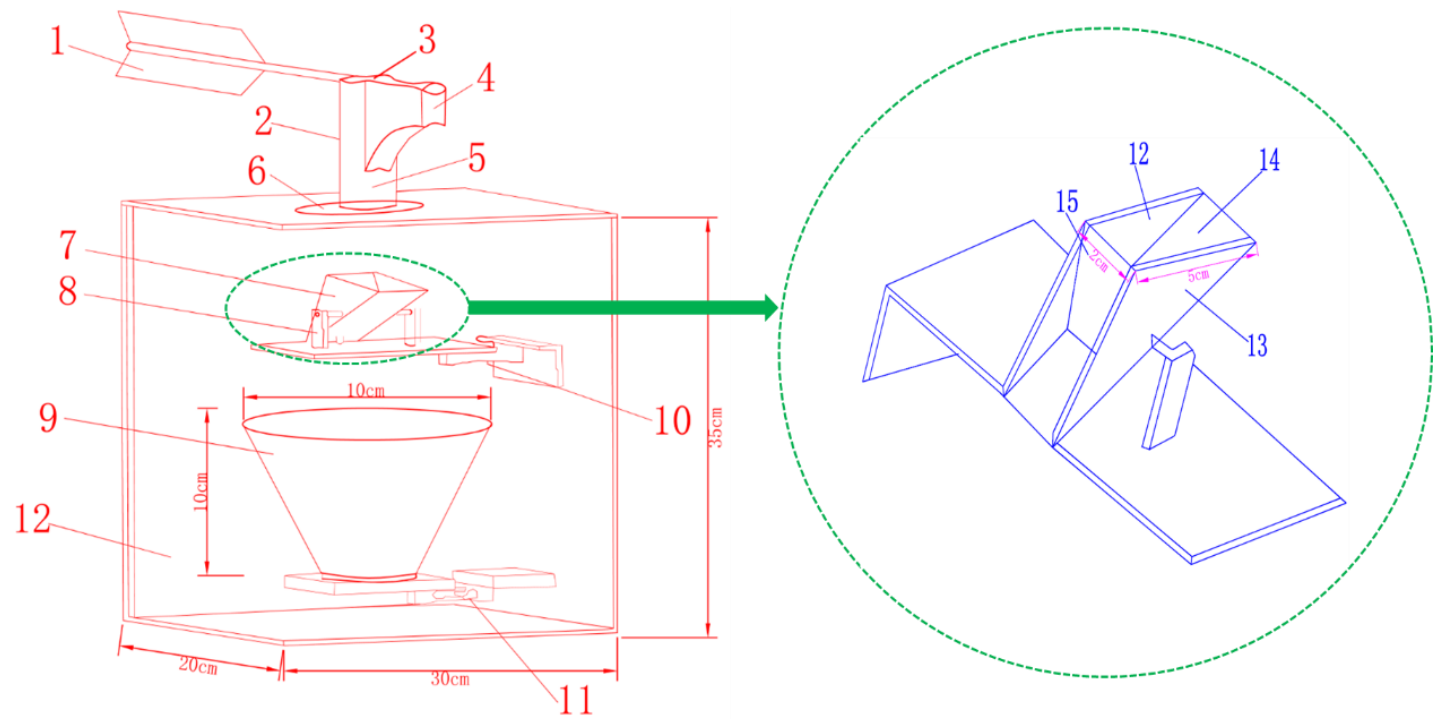

Figure 2. Structure diagram of the fully automated high-precision sand collector: 1 . empennage; 2 . first air leakage network; 3. second air leakage network; 4. sand intake valve; 5 . hollow shaft; 6 . bearing dust proof seat; 7 . smallcapacity container; 8 . container support shaft; 9 . large-capacity container; 10 . small-range, high-precision weighing sensor; 11. large-scale weighing sensor; 12 . first triangular plate; 13 . second triangular plate; 14 . first rectangular plate; 15 . second rectangular plate.

During the tests, the empennage kept the sand intake rate consistent with the wind direction according to the wind force in the wind direction. At this point, the surface sands entered the hollow shaft through the sand intake valve. Sand-carrying gas flows could be discharged from the first air and second air leakage networks. Sands then automatically sank to the small-capacity container via gravity, and the sand weighting sensor began to sense (accuracy: $20 \mathrm{mg}$ ). The weight data were subsequently uploaded to the data acquisition system. Then, the aspect sensor uploaded the aspect data of the acquired sand to the data acquisition system to obtain the instantaneous sand amount in the corresponding direction. If the collected sands were over $240 \mathrm{~g}$, the tipping bucket rotated automatically to pour the sands into the large-capacity container for weighing (weight range: $0-10 \mathrm{~kg}$ ). Not only was the total sand amount in the whole process recorded, but also the data measured by the small capacity sensor were calibrated, realizing long-term automatic monitoring, and reducing the manual workload. The data acquisition system was connected to a GPRS/CDMA communication module and power supply system, and the GPRS/CDMA communication module was wirelessly connected with the computer, with which real-time online observations were achieved offsite or onsite. The observation frequency was up to $10 \mathrm{~Hz}$. All the data measured during an experiment, including wind speed, wind direction, sand transport aspect, instantaneous aspect sand flux, profile sand flux, and cumulative total sand flux, were uploaded to the data acquisition system. Through the wireless transmission network, the backstage carried out real-time remote automatic monitoring of the acquired data.

\subsection{Data Collection and Processing}

Fifteen dust events from July to August in 2010 were studied. Blowing sands and sandstorms are frequent in this area, which facilitated the collection of experimental data. The automatic sand sampler developed by [46] (Figure 2) was used, which had a sand intake area of $5 \mathrm{~cm} \times 2 \mathrm{~cm}$ and a collection frequency of $1 \mathrm{~Hz}$. An H11-B wind erosion 
sensor (H11-Sensit, American SENSIT Company: Valparaiso, IN, USA) (Figure 3) was used to record the number of sand particles impacting the sensor every second. The sensor probe was installed $5 \mathrm{~cm}$ above the ground. The sand sampler was mounted on a horizontal sand surface with a straight-line distance of $50 \mathrm{~m}$ from the wind erosion sensor to ensure that the sand sampler empennage could rotate normally on windy days. The sand intake height of the sand sampler was the same as the height of the sensor probe. A national standard test sieve was used for statistics.

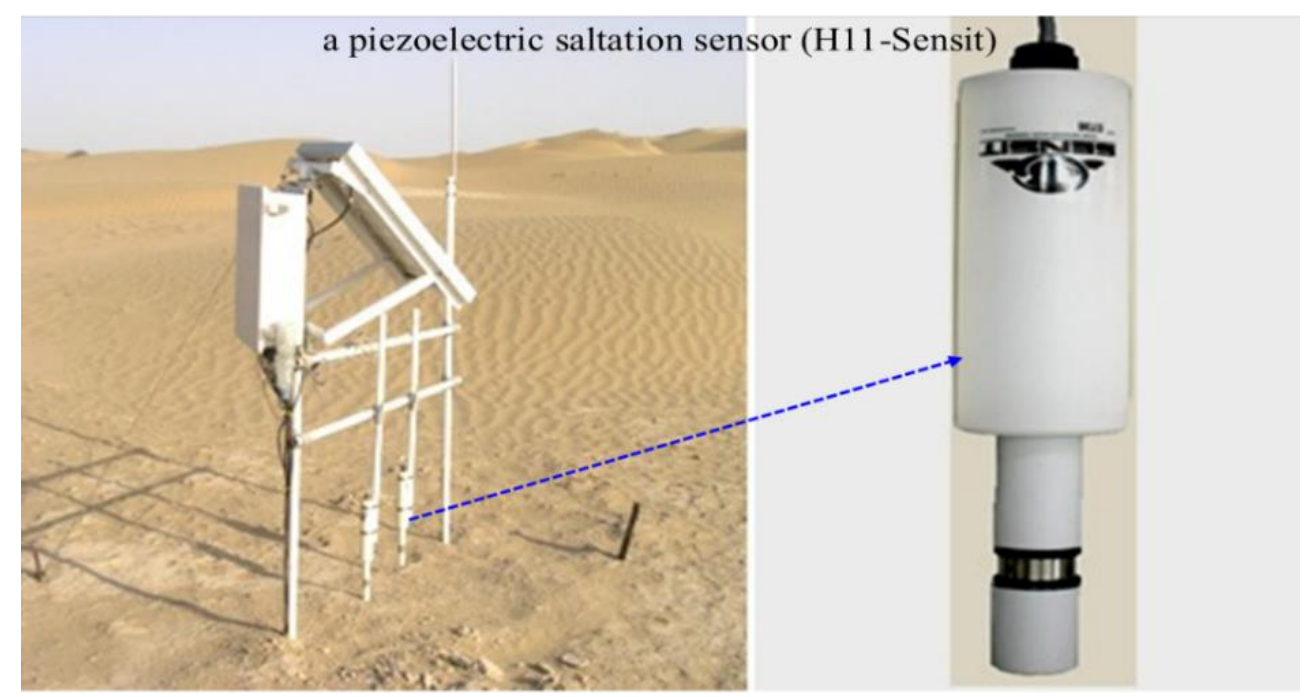

Figure 3. Wind erosion sensor (H11-Sensit).

The average particle size of sands was measured to be $63-250 \mu \mathrm{m}$. Sands with particle sizes greater than $74 \mu \mathrm{m}$ accounted for $75.57 \%$, and those with particle sizes greater than $50 \mu \mathrm{m}$ accounted for $97.65 \%$. The average of the two was $86.61 \%$. The actual sand collection multiplied by $86.61 \%$ was the effective weight corresponding to the number of sand particles impacting the sensor. After the experiment, the SigmaPlot12.5 software was used for data processing and plotting.

Yang and He showed that the number of sands particles impinging the sensor $(N)$ and the dust horizontal flux $(F)$ have a linear relationship:

$$
F=0.0512 N
$$

At the same time, the sand collection of the BSNE sand sampler at $5 \mathrm{~cm}$ above the ground $(y)$ and the number of sand particles impacting the sensor $(x)$ also had a linear relationship:

$$
y=0.0002 x
$$

Equations (1) and (2) were combined to obtain the following equation:

$$
F=256 M
$$

where $M$ is the mass of sand collected within $5 \mathrm{~cm}$ above the ground (units: $\mathrm{kg}$ ), $N$ is the number of sand particles impacting the sensor (in units of $10^{3}$ ), and $F$ is the horizontal flux of dust passing through the $5 \mathrm{~cm} \times 2 \mathrm{~cm}$ section (units: $\mathrm{kg}$ ).

In our experiments, the number of sand particles impacting the sensor and the mass of collected sand were found to have a linear relationship, as found by $[47,48]$ and described by Equation (2). Therefore, the dust horizontal flux in this paper was calculated using Equation (3). Next, the sand collection efficiency is the ratio of the amount of sand collected by the sand sampler over the actual amount of transported sand. The correlation coefficient of the two was taken here as the average sand collection efficiency. 


\section{Results and Analysis}

\subsection{Analysis of the Correlation between the Number of Impacted Particles and the Amount of Sediment Collected}

Fifteen typical sand-dust weather events from July to August 2015 were monitored to analyze the variation trend of the impacting particle number and sediment concentration. It was found that the variation trend was consistent between sand-dust storms and sand-blown weather, especially on 19 July 2015 (8:35-21:35), 4 August 2015 (11:35-21:15), 5 August 2015 (10:20-20:25), and 7 August 2015 (9:30-21:55) (Figure 4). It was inferred that the variation trend of the impact particle number and sediment concentration was almost consistent for any kind of sand-dust weather, indicating that the field sediment collection performance of the automatic high-precision sand collector was good for both sand-dust storm weather and sand-blown weather.

Figure 5 shows the relationship between the total number of impacting particles and the total sediment concentration corresponding to the 15 dust weather events. It was found that there is a statistically significant linear relationship between the total number of impact particles and the total sediment concentration, where the correlation coefficient, $R$, reached 0.9608. If the sand sampler failed for a short while, the linear equation $y=0.0002 x$ was used to estimate the sediment concentration at a height of $5 \mathrm{~cm}$ in the corresponding time using the number of particles impacting the sensor, so as to verify the reliability of the weighing.

A regression analysis was carried out on the treated sediment concentration data and impacting particle number data by fitting an exponential function, logarithmic function, power function, and linear function to the data. The best-fitting results are shown in Table 1. From the 15 sets of fitting results, the fitting degrees of the linear function and power function were higher than those of the logarithmic function and exponential function. The linear function has 11 times higher results than the power function, and the average was higher than the power function. Therefore, the linear function could better describe the correlation between the number of sand particles impacting and the sediment concentration; that is, the optimal relationship between the number of sand particles impacting and the sediment concentration during each five-minute period was linear.

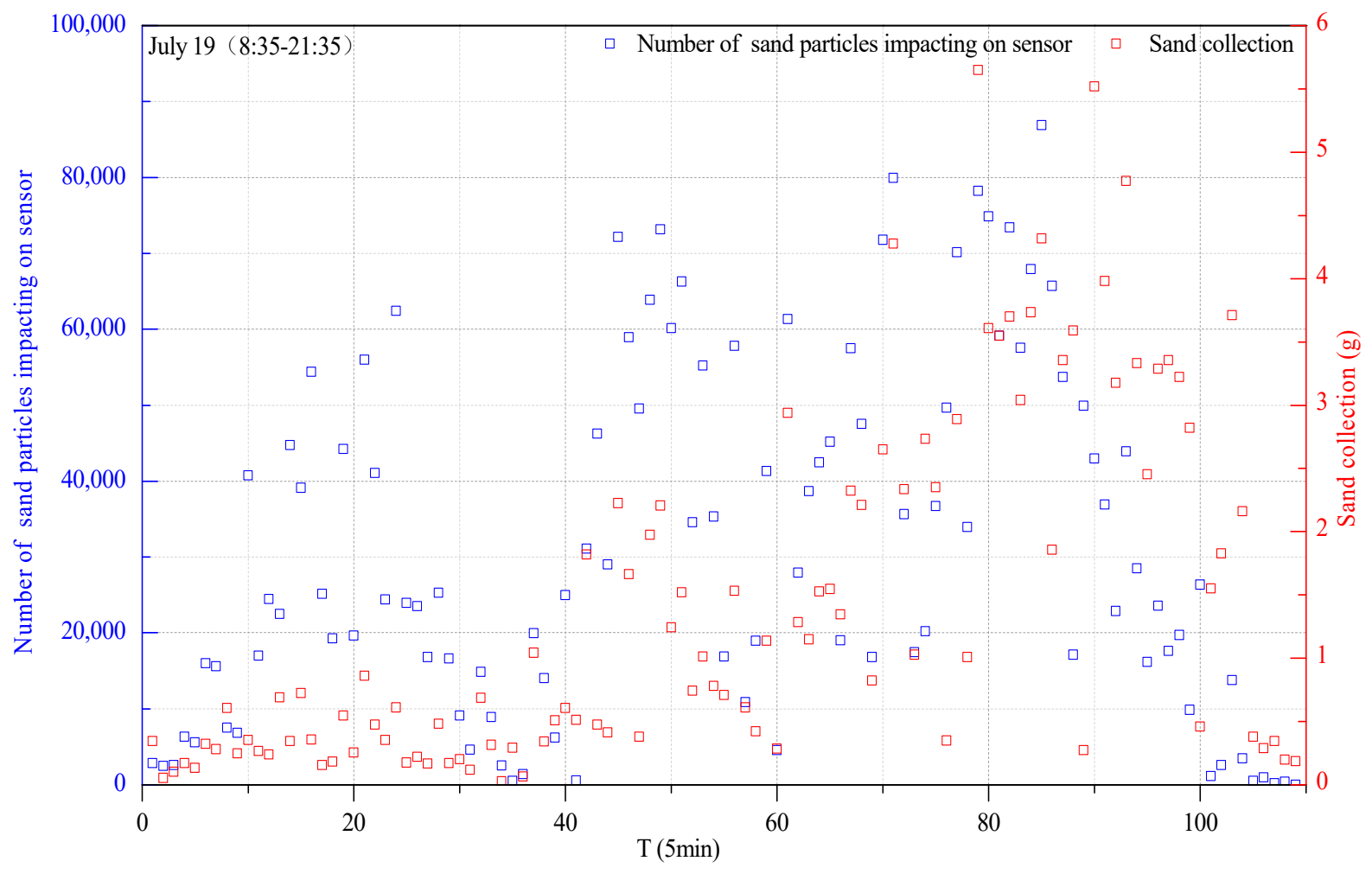

Figure 4. Cont. 

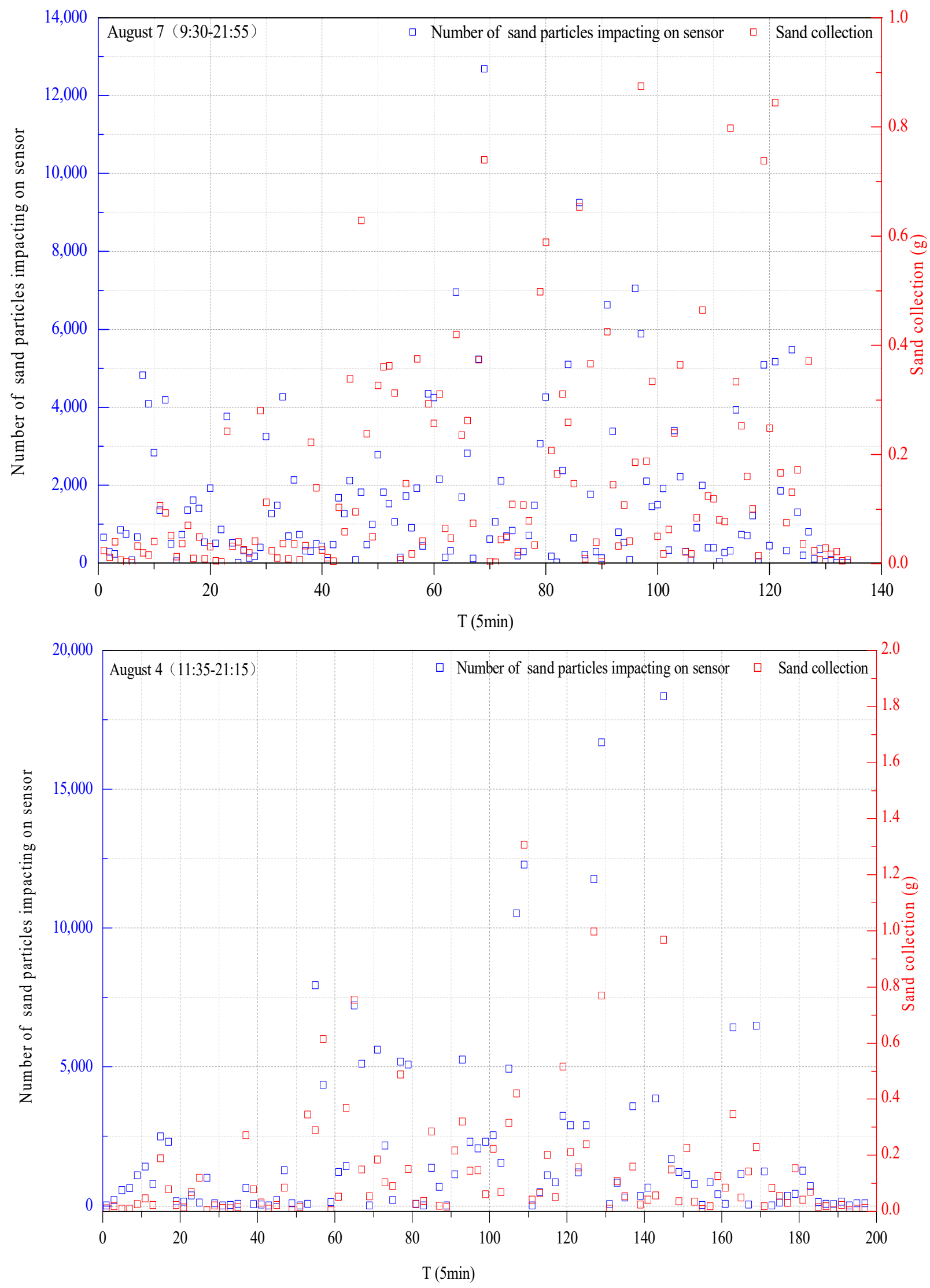

Figure 4. Cont. 


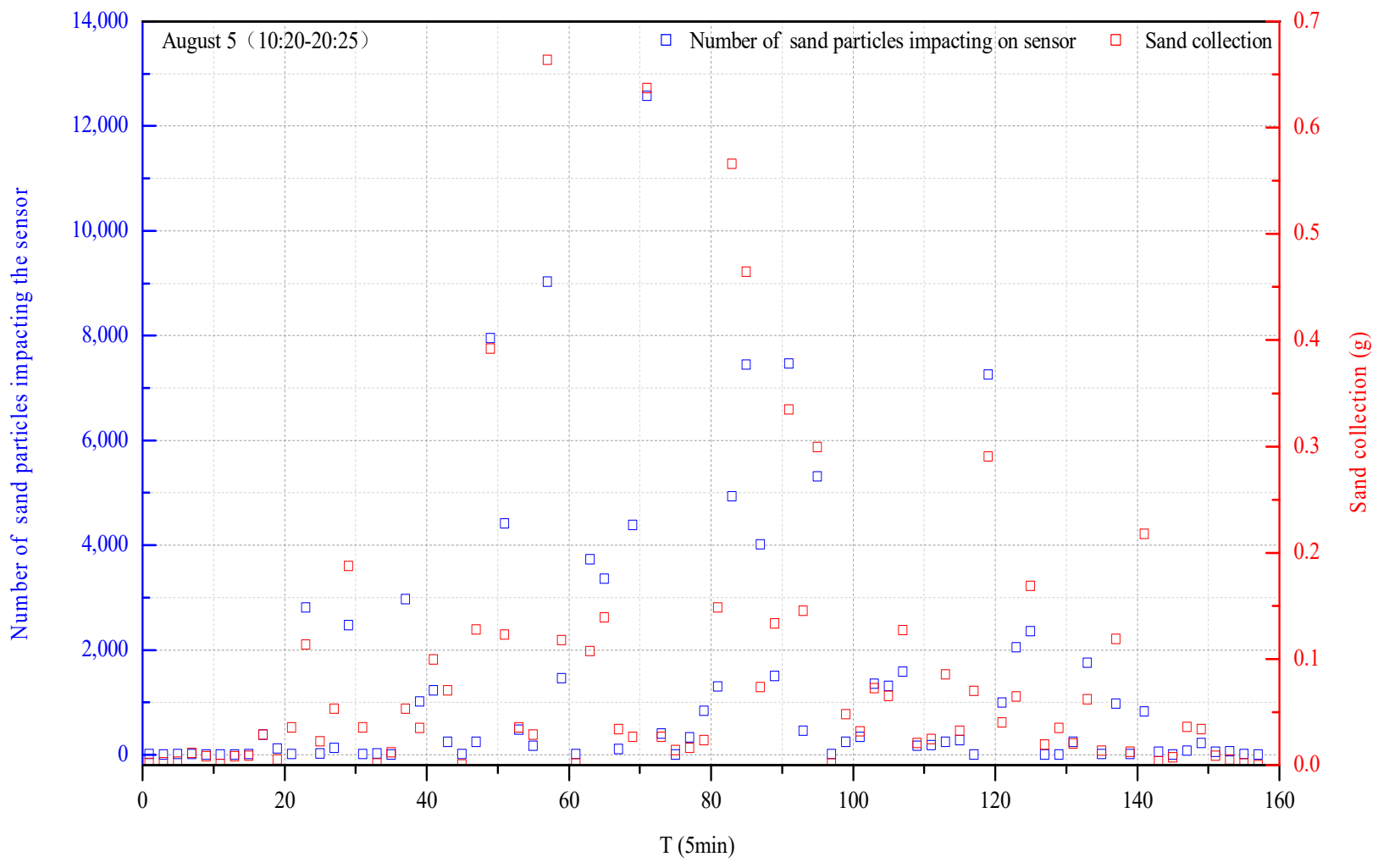

Figure 4. Trends in the number of impact particles and the amount of sediment collected.

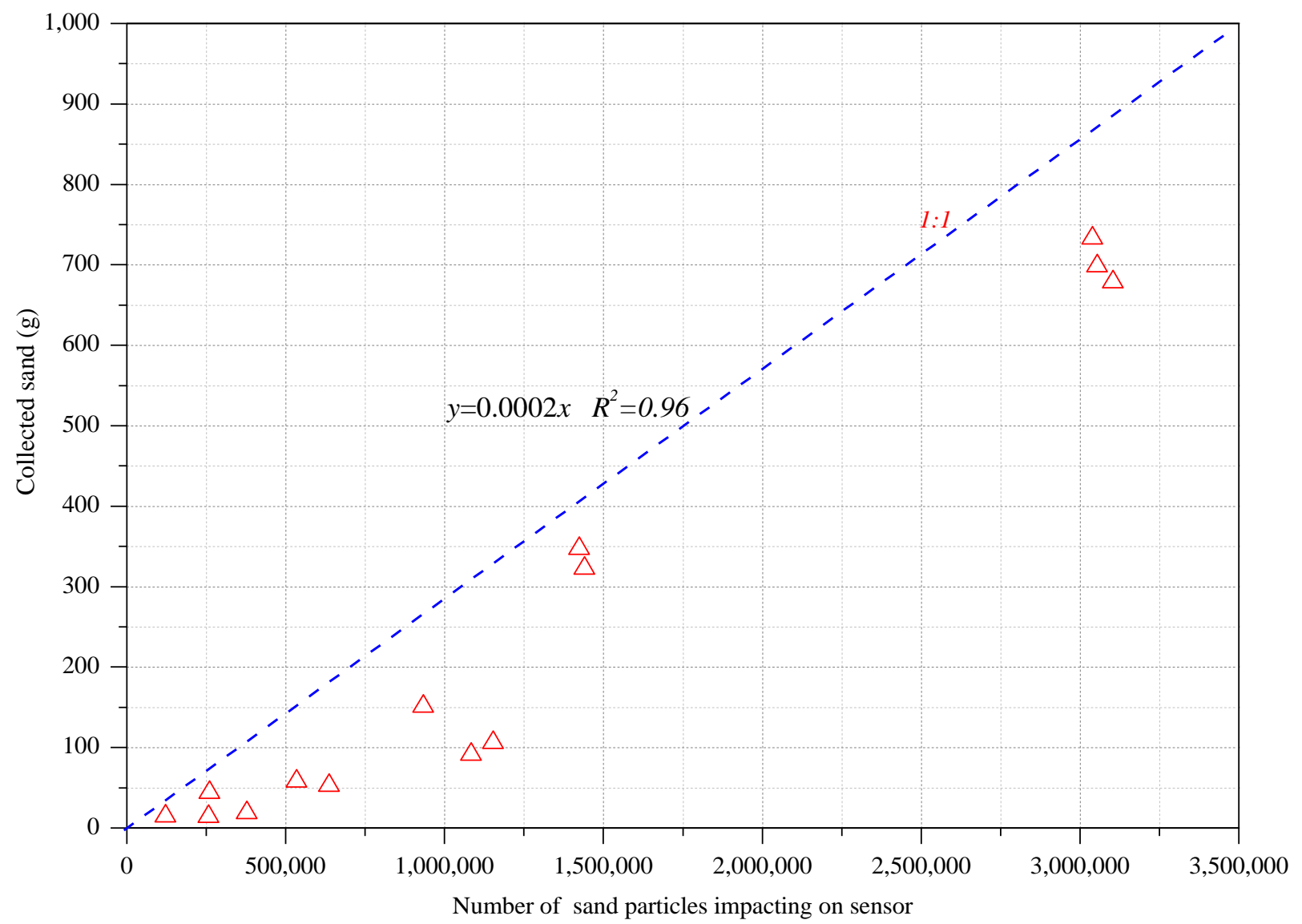

Figure 5. Correlation between the total impact particle number and total sediment concentration. 
Table 1. Fitting analysis of saltation particle numbers and sand collection quantity.

\begin{tabular}{llcccc}
\hline & & \multicolumn{4}{c}{ Coefficient of Determination $\left(\mathbf{R}^{2}\right)$} \\
\cline { 3 - 6 } Observation Time & $\begin{array}{c}\text { Exponential } \\
\text { Function }\end{array}$ & $\begin{array}{c}\text { Logarithmic } \\
\text { Function }\end{array}$ & $\begin{array}{c}\text { Power } \\
\text { Function }\end{array}$ & $\begin{array}{c}\text { Linear } \\
\text { Function }\end{array}$ \\
\hline \multirow{4}{*}{ July } & $19(8: 35-21: 25)$ & 0.45 & 0.62 & 0.69 & 0.6 \\
& $20(19: 35-21: 25)$ & 0.33 & 0.18 & 0.26 & 0.28 \\
& $21(20: 20-22$ day5:25) & 0.32 & 0.34 & 0.45 & 0.60 \\
& $29(22: 15-30$ day 2:15) & 0.44 & 0.3 & 0.55 & 0.69 \\
August & $31(13: 10-8.1$ day 7:10) & 0.34 & 0.25 & 0.35 & 0.49 \\
\hline $1(21: 40-23: 25)$ & 0.63 & 0.68 & 0.75 & 0.82 \\
& $4(11: 35-21: 15)$ & 0.44 & 0.31 & 0.43 & 0.72 \\
& $5(10: 20-20: 25)$ & 0.32 & 0.38 & 0.53 & 0.78 \\
& $7(9: 30-21: 55)$ & 0.26 & 0.24 & 0.25 & 0.38 \\
& $8(10: 35-20: 25)$ & 0.28 & 0.48 & 0.55 & 0.44 \\
& $1(13: 15-18: 05)$ & 0.60 & 0.31 & 0.44 & 0.84 \\
& $13(10: 30-21: 25)$ & 0.33 & 0.27 & 0.32 & 0.63 \\
& $14(10: 00-21: 15)$ & 0.43 & 0.31 & 0.64 & 0.47 \\
& $18(10: 50-20: 50)$ & 0.41 & 0.21 & 0.68 & 0.58 \\
& $20(13: 40-19: 55)$ & 0.54 & 0.29 & 0.56 & 0.75 \\
\hline
\end{tabular}

According to the linear regression analysis of the number of sand particles impacting every $5 \mathrm{~min}$ and the amount of sand collected during this period, it was found that the average correlation coefficient $R$ is 0.7702 . According to the judgment standard, $0.3<|R|<0.5$ is referred to as a weak correlation, $0.5<|R|<0.8$ is referred to as a significant correlation, and $0.8<|R|<1$ is referred to as high correlation. Thus, it can be seen that among the 15 fitting results, nine were significantly correlated, and six were highly correlated. This showed that the linear correlation between the number of sand particles impacting the sensor and the sediment mass was good.

From an energy point of view, the energy gained by impacting particles during windblown sand events is extremely complex, especially in the field, where the impacting particles generally acquire mechanical energy and horizontal kinetic energy in the airflow. According to the conservation of energy theorem, the amount of energy lost by the mass should yield reliable and accurate experimental results.

\subsection{Sand Collection and Sand Collection Efficiency}

The number of sand particles impacting the sensor during the 15 dust events and the theoretical values of the collected sand masses in Table 2 were fitted, and, as before, the moving particles in the airflow are approximately equal to the energy lost as they impact the sensor; this energy can be ascertained by monitoring the total energy of the impacting particles per second at a certain height. In different periods of the 15 dust events, different wind drift sand flows were observed, which were influenced by the wind speed and sand source supply condition, which resulted in different fitting functions for the number of sand particles impacting the sensor and the amount of collected sand. Therefore, two or more functions should be combined when studying the relationship between the number of sand particles impacting the sensor, and the collected sand results were well-described by a linear relationship. The coefficient of determination, $R^{2}$, was 0.6 (Figure 6). Therefore, the theoretical value of the collected sand mass in each dust event could be calculated according to the fitted linear equation. The calculated results are also shown in Table 2. The statistical results showed that the theoretical values were smaller than the observed values. The reason for this may be that the data described by the linear relationship do not perfectly follow the best-fitting line, but are distributed about it. The field test and wind tunnel test data were different, so the correlation coefficient was not 1 and it was inevitable that the theoretical value of sand collection was smaller than the observed value. 
Table 2. Observed saltation particle numbers and observed and theoretical sand masses.

\begin{tabular}{llccc}
\hline Observation Time & $\begin{array}{c}\text { Impact Number } \\
\text { of Particles }\end{array}$ & $\begin{array}{c}\text { Observed Value } \\
\text { of Sediment/g }\end{array}$ & $\begin{array}{c}\text { Theoretical Value } \\
\text { of Sediment } \\
\text { Quantity/g }\end{array}$ \\
\hline \multirow{3}{*}{ July } & $19(8: 35-21: 25)$ & $2,936,905$ & 743.4966 & 587.3810 \\
& $20(19: 35-21: 25)$ & $3,407,661$ & 154.126 & 681.5322 \\
& $21(20: 20-22$ day 5:25) & 920,676 & 170.5492 & 184.1352 \\
& $29(22: 15-30$ day 2:15) & 147,786 & 34.6005 & 29.5572 \\
& $31(13: 10-1$ day 7:10) & $1,050,073$ & 179.586 & 210.0146 \\
\hline \multirow{4}{*}{ August } & 19,772 & 4.5764 & 3.9544 \\
& $1(21: 40-23: 25)$ & 195,696 & 26.6128 & 39.1392 \\
& $4(11: 35-21: 15)$ & 116,005 & 12.3933 & 23.201 \\
& $5(10: 20-20: 25)$ & 231,534 & 43.2746 & 46.3068 \\
& $7(9: 30-21: 55)$ & $1,048,891$ & 118.5805 & 209.7782 \\
& $9(13: 15-18: 25)$ & $1,380,718$ & 354.3815 & 276.1436 \\
& $13(10: 30-21: 25)$ & 210,702 & 14.2759 & 42.1404 \\
& $14(10: 00-21: 15)$ & 390,274 & 25.0633 & 78.0548 \\
& $18(10: 50-20: 50)$ & 293,093 & 15.7758 & 58.6186 \\
& $20(13: 40-19: 55)$ & 349,610 & 4.5021 & 69.922 \\
\hline
\end{tabular}

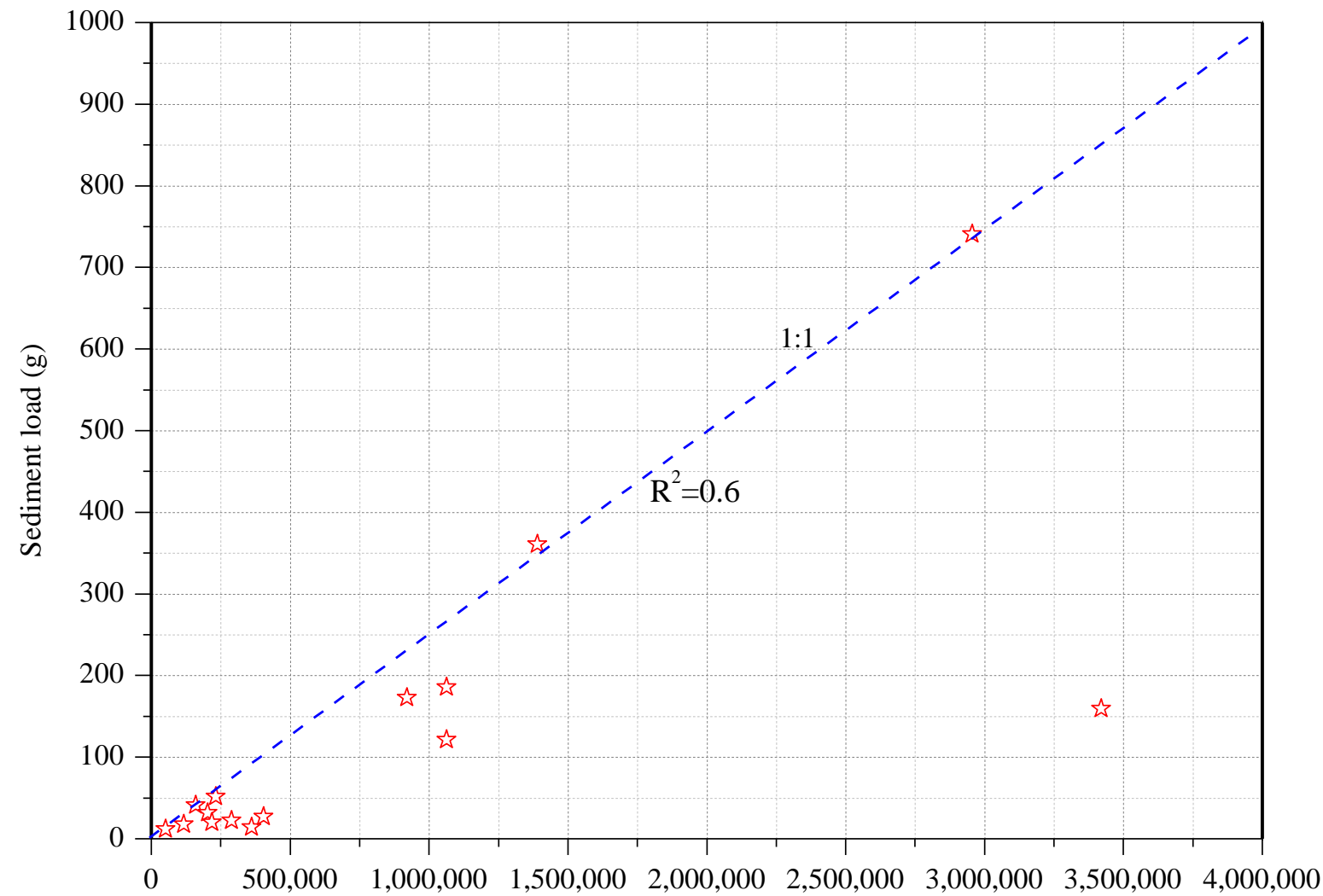

Number of sand particles impacting the sensor

Figure 6. Change of sand collection quantity with saltation particle numbers.

As shown in Figure 7, the theoretical and observed sand masses were fitted and analyzed, and the two did not show any linear relationship, with a $R^{2}$ of only 0.40 , indicating the large difference between the observed and theoretical values. The reason for this large discrepancy was that the theoretical values were calculated based on the actual amounts of collected sand and the number of sand particles impacting the sensor. In addition, the field 
environment was complex, which resulted in errors of the data acquisition system in the transmission process, which reduced the final mass accuracies.

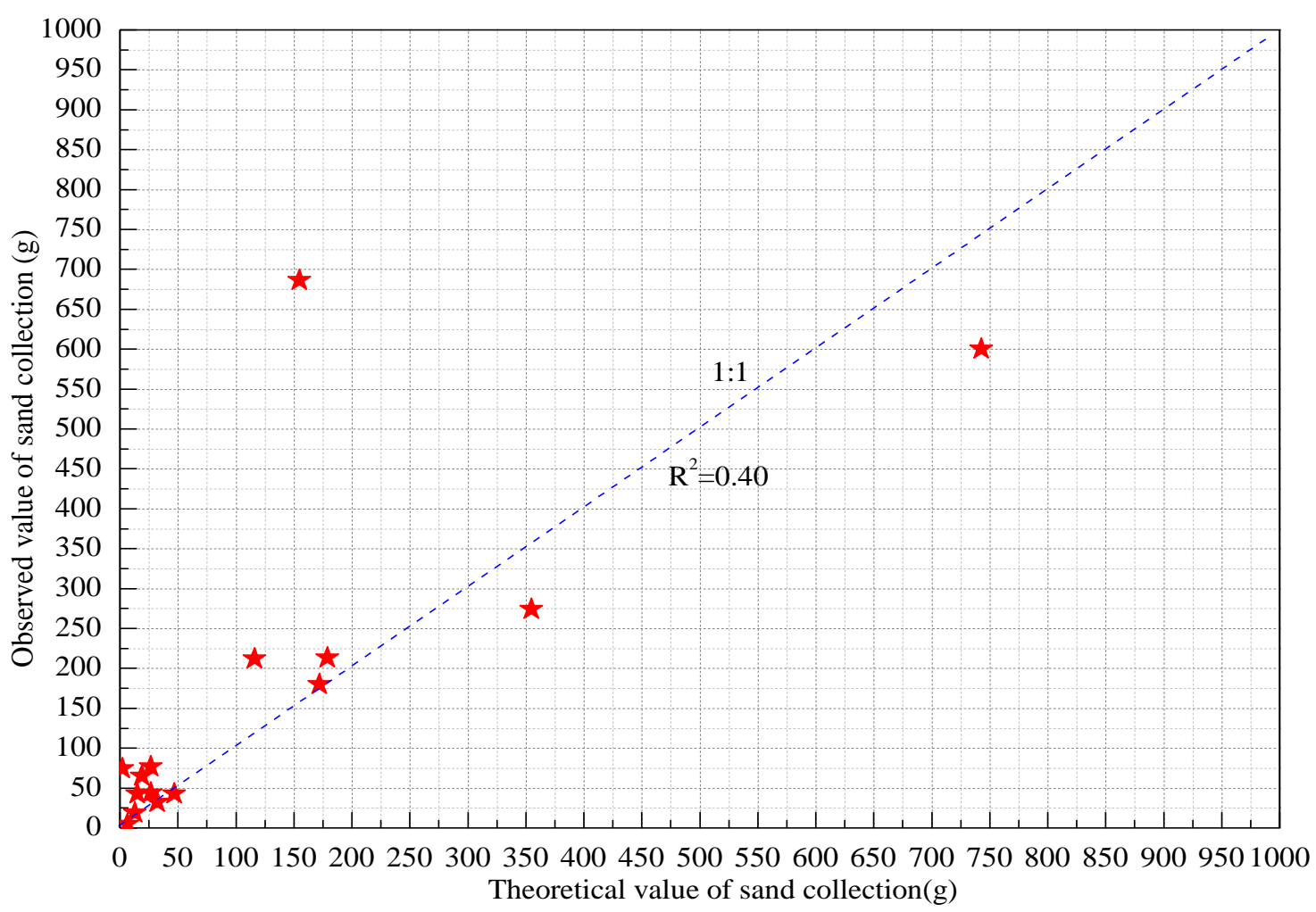

Figure 7. Relationship between theoretical and observed sand masses.

A similar study found that their active sand sampler had a higher sand collection efficiency than their passive sand sampler in wind tunnel experiments, and found that the sand collection efficiency increased with an increase of grain size [49]. He et al. found that the sand collection efficiency of their active sand sampler was $105 \%$ with the error of $\pm 5 \%$ [46]. The sand collection efficiency of their passive Leach sand sampler was $85 \%$, and the collection efficiency for sands with particle sizes smaller than $10 \mu \mathrm{m}$ was $70 \%$. Their Fryrear BSNE sand sampler had a 90\% $\pm 5 \%$ collection efficiency for aeolian sands and a $40 \%$ collection efficiency for sands with particle sizes smaller than $10 \mu \mathrm{m}$. Goossens et al. found that their same sand sampler had a higher efficiency for collecting aeolian sands than for collecting dust [47-49], where the larger the size of the collected particles, the higher the collection efficiency of the sand sampler. Therefore, even for the same type of sand samplers, the sand collection efficiency may be different due to different test methods. For example, one experiment showed that the BSNE sand sampler had a sand collection efficiency of 100-120\% [48], while Xu et al. concluded that their BSNE sand sampler had a sand collection efficiency of $90 \%$ [49]. Although it was impossible to calculate the sand collection efficiency of each dust event directly based on the observed sand masses and the theoretical values of the sand masses in this work, the average sand collection efficiency could be calculated according to the correlation coefficient between the two: the average sand collection efficiency of the sand sampler at a height of $5 \mathrm{~cm}$ was $94.3 \%$. Therefore, the method of testing the efficiency of sand samplers is a problem worth further studying.

\subsection{Sand Dust Horizontal Flux Calculation}

The dust horizontal fluxes were calculated with Equation (3). The variation of particle size and wind speed likely affect the distribution of the dust horizontal fluxes. When the sand particle size was large, the transition height was also high, and the corresponding sand collection flux was also large. It can be seen from Figure 8 that during the 15 dust 
events, the maximum dust horizontal flux is $190.335 \mathrm{~kg}$, which was measured during a sandstorm. The other events were all blowing sand events, with a minimum value of about $1.2 \mathrm{~kg}$. As these experiments were conducted at the same sampling site, and over a continuous sampling period, the impact of particle size was not taken into consideration in our study; instead, only the impact of wind speed was considered. Unfortunately, more useful information was lost after the wind speeds were averaged. Therefore, the transport of most dust materials happened in the surface layer and they landed on the Earth's surface by short-distance transportation. Even during a sandstorm, only a small amount of dust was transported at higher altitudes. Thus, when calculating the horizontal dust flux, its functional relationship with height should be established. In this study, the relationship between the collected sand within a height of $5 \mathrm{~cm}$ from the ground by the sand sampler and the horizontal dust flux was used; specifically, the former was used to calculate the latter using Equation (3) via a simplified calculation method that reduced the computational requirements.

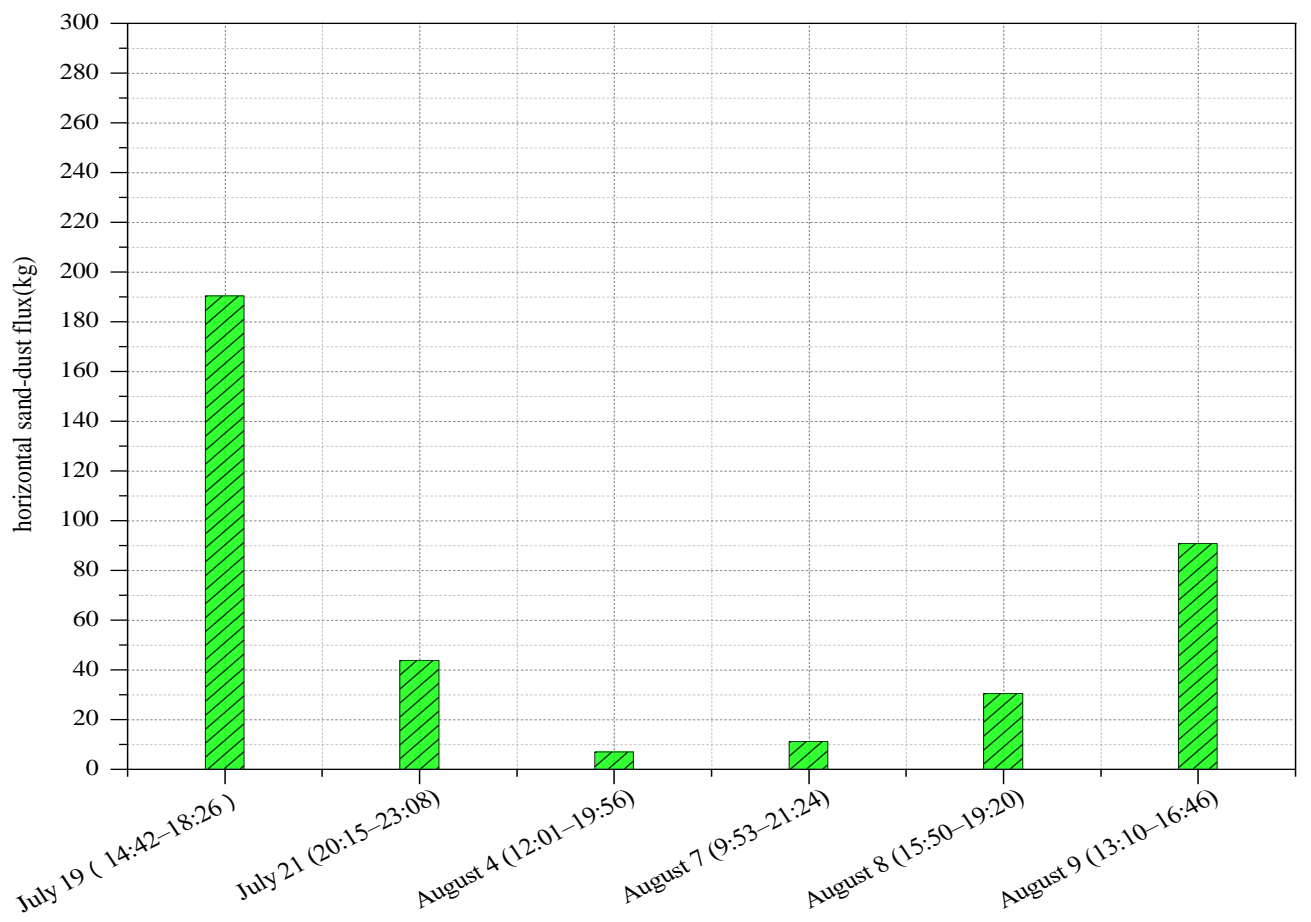

Figure 8. Horizontal sand-dust fluxes on selected dates.

The dust horizontal fluxes were calculated with Equation (3). The variation of particle size and wind speed likely affect the distribution of the dust horizontal fluxes. When the sand particle size was large, the transition height was also high, and the corresponding sand collection flux was also large. It can be seen from Figure 8 that during the 15 dust events, the maximum dust horizontal flux is $190.335 \mathrm{~kg}$, which was measured during a sandstorm. The other events were all blowing sand events, with a minimum value of about $1.2 \mathrm{~kg}$. As these experiments were conducted at the same sampling site, and over a continuous sampling period, the impact of particle size was not taken into consideration in our study; instead, only the impact of wind speed was considered. Unfortunately, more useful information was lost after the wind speeds were averaged. Therefore, the transport of most dust materials happened in the surface layer and they landed on the Earth's surface by a short distance.

\subsection{Sand Transportation Rate and Wind Speed}

Figure 9 shows the relationship between the sand transportation rate and wind speed under different dusty weather conditions; (a) and (b) were strong and typical sandstorm 
weather events, respectively, and (c) to (j) were blowing sand weather events. In general, the rate of sand-dust transport increased with an increase of wind speed, but the changing trends of the wind speed and sand-dust transport rate during some weather processes were inconsistent. For example, for some blowing sand events (e, g, i, and j) and strong sandstorm events ( $a$ and $b$ ), although the wind speeds were small, the variations of the sand transportation rate were large. The soil temperature at $0 \mathrm{~cm}$ during the corresponding events showed that the soil temperature rapidly increased with an increase of solar radiation intensity. In the surface layer, a strong decreasing temperature structure formed in the surface layer, and the thermal turbulence became stronger and stronger, resulting in enhanced heat transfer and unusually active sand saltation. When the wind speed was small, but the sand transportation rate was relatively large, the corresponding soil temperature at $0 \mathrm{~cm}$ was hot. This showed that the increased soil temperature at $0 \mathrm{~cm}$ could promote the saltation of sands. This finding is consistent with the results of [48], who found that the "synchronization of wind and temperature" was in favor of the co-occurrence of wind and saltation. The specific relationship of the sand transportation rate with wind speed and temperature needs to be further studied.

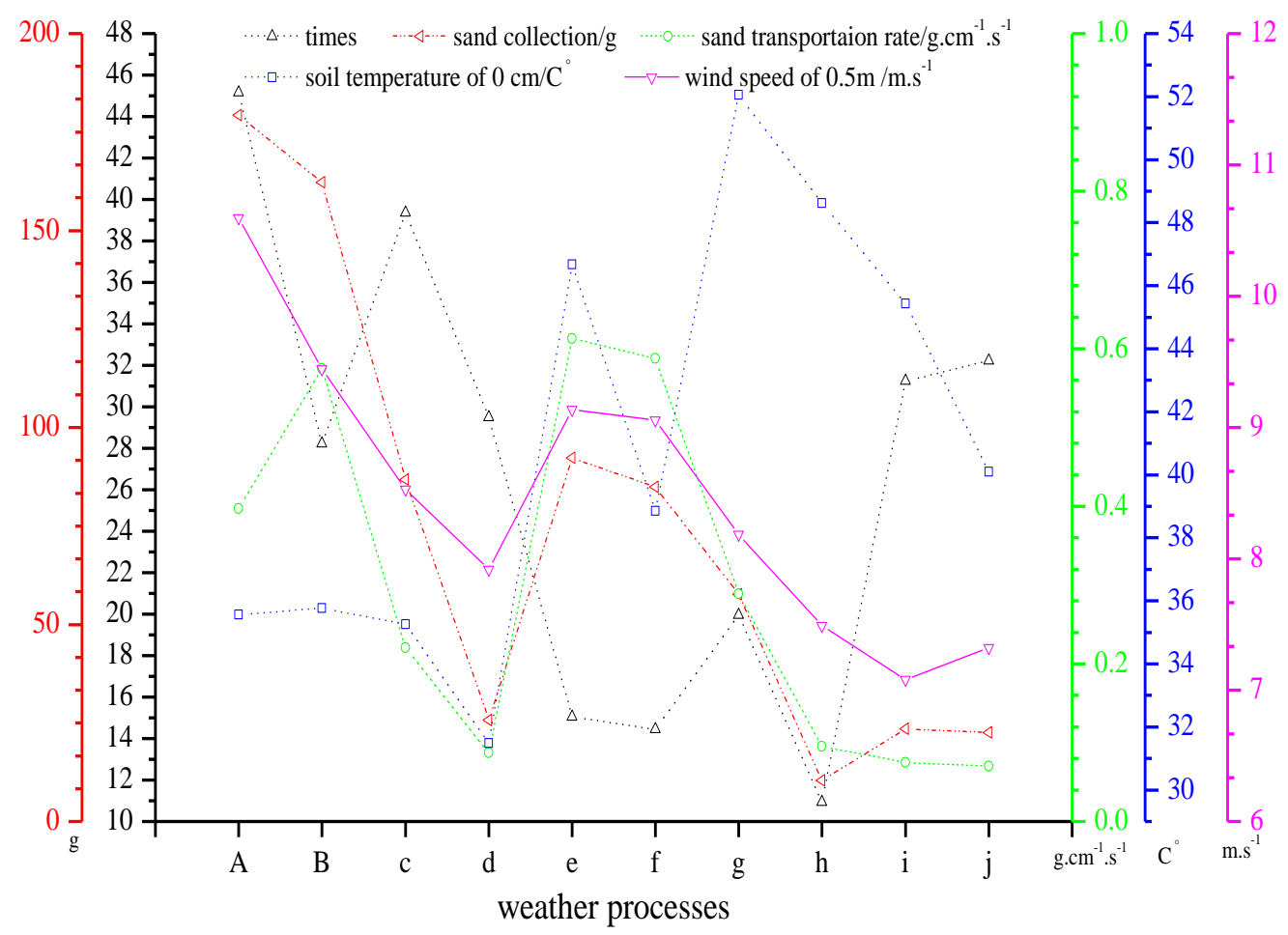

Figure 9. Sediment of different dust events.

\section{Discussion}

There are many factors affecting the horizontal flux of sand dust. In addition to differences in collection instruments, there are many other factors, especially in terms of physical mechanisms, which are summarized in the following.

The movement of sand dust in response to wind is the most important feature of aeolian sediment transport. Wind accelerates particles and ejects more particles when impacting a surface, which leads to increases in the horizontal dust flux in the initial stages $[50,51]$. However, this rapid increase in the impact particle concentration produces a corresponding increase in the drag of dust particles on the fluid, thereby retarding the wind speed. This in turn reduces the speeds of the horizontal dust flux particles, such that a steady state is reached when the speeds of the impacting particles are reduced to a value at which there is a single particle leaving the soil surface for each particle impacting 
it [52]. Because of the finite response time of dust flux particle speeds to the wind speed, the horizontal dust flux can "overshoot" the eventual steady-state mass flux [53-55].

Kok, Parteli, and Michaels found that the wind profile was modified through momentum transfer by impacting particles [14]. On the one hand, it is the retardation of the wind profile through drag by the saltating particles that ultimately limits the number of particles that can be saltated under given conditions. On the other hand, the drag produced by saltating particles reduces the horizontal momentum flux carried by the wind. At the same time, although the particle speeds at the surface were once thought to remain constant, numerical simulations and wind-tunnel measurements have shown that the particle speeds increase as a function of the shear velocity above the surface. This means that the mass flux higher up in the saltation layer increases relative to that in lower layers, producing a slight increase in the saltation layer height with shear velocity. The extraction of wind momentum by saltating particles produces a steady-state wind profile that accelerates saltating particles to a saltate speed that, on average, results in a single particle leaving the soil bed for each particle impacting upon it.

Rice, Willetts, and McEwan found that, when the surface shear stress fell below the impact threshold, fewer saltate particles were entrained by the wind. This in turn reduced the transfer of momentum from the fluid to the impacting particles, thereby increasing the surface shear stress back to its threshold value. Conversely, when the surface shear stress exceeded the threshold value, more saltating particles were entrained, again restoring the surface shear stress to its critical value. Experiments have indicated that particles with a larger cross-sectional area have a correspondingly higher chance of being "splashed" by a saltate particle [56]. Saltate particles may have short lifetimes because their high inertia causes them to attain lower speeds when splashed, leading them to quickly settle back to the dust surface [57]. Actually, winds cannot directly lift dust particles because the corresponding interparticle cohesive forces are large compared to aerodynamic forces. Instead, these dust particles mainly collide with each other under wind erosion [58,59]. During a dust storm, lifted particles are accelerated by the wind, and the resulting impacts on the dust bed can eject, or splash, new erosion particles into the fluid stream. This process produces an exponential increase in the particle concentration [60], which leads to increasing drag on the wind, thereby retarding the wind speed in the erosion layer [61]. It is this slowing of the wind that acts as a negative feedback process that reduces particle speeds, which ultimately limits the number of impacting particles [62].

Dust flux is predominantly emitted by the saltates of eroding particles at the near surface [58,59]. Several authors have also argued that mid-air collisions can affect particle trajectories and the mass flux at large shear velocities [63-66]. Wind erosion produced by colliding particles during a single hop is of the order of $10-50 \%$, which increases with wind speed [66]. That is, even at large impact speeds, not all saltating particles rebound from the surface, because some will dig into the particle bed [67]. Moreover, recent measurements indicated that the restitution coefficient is a declining function of the saltator impact speed [68]. Numerical simulations [50,53,69,70], laboratory experiments [71], and theory [57] have all indicated that the number of splashed particles scales with the impacting momentum. Experiments have also indicated that the fraction of the average impacting momentum spent on splashing surface particles is of the order of $15 \%$ for a bed of loose sand particles $[56,57,59]$. Most splashed particles, therefore, move in low-energy reptation trajectories and quickly settle back to the soil bed. However, some splashed particles do gain enough momentum from the wind to participate in saltation and splash up more particles. This multiplication process produces a rapid increase in the particle concentration upon initiation of saltation, where the distribution of splashed speeds at a given ejected velocity follows either an exponential or a lognormal distribution [72,73].

Sand transport has been measured by many instruments developed mainly to determine the rates of transported material. Accurately measuring these processes has been an ongoing challenge since the first known discrete measurements were made by Bagnold. In general, impact sensors suffer from poor sensitivity to small sand grains [74], and in 
the case of Safire, poor interinstrument repeatability [75]. Over the past decade, although instruments vary in design and complexity, they can be split into two categories: integrating and real-time electronic instruments. As achieved in this study, there have been incremental improvements in this latter category of devices that have been motivated, in part, by the observation that sediment transport occurred on spatial scales smaller than $5 \mathrm{~cm}$ and temporal scales shorter than $1 \mathrm{~s}$. Initial designs were improved by increasing the efficiency by taking account of the aerodynamics associated with blocking a portion of the flow [13]. Additional improvements were made by increasing the temporal resolution through automatic weighing systems $[27,28]$. However, the spatial and temporal resolutions of a mass-collecting sediment trap remain insufficient for capturing most small-scale aeolian processes. In addition, because sand traps obstruct the flow to varying degrees, the efficiency of sampling saltating grains varies with height and wind conditions [17] but is generally around $80 \%$ [44]. Sand particle sizes not only differ regionally [76], but also vary significantly with height [77-79]. This variation of sand particle size with location and height inevitably influences the sampling efficiency of different samplers, leading to errors in the amount of aeolian sand collected. However, in previous experiments, this has often been neglected, or a fixed sampling efficiency has been applied [48,80-82].

Some research has shown that an exchange of sand is expected between adjacent dunes of different heights, since larger dunes are more likely to disperse sand than smaller ones [83]. Changes in individual dunes relative to sand flux are unstable, meaning that in one area, dunes that evolve only through sand flux should eventually merge into larger dunes [84]. It is well-known that dune patterns are mainly determined by the amount of available sand and the behavior of the wind in the year. At the same time, changes in the wind and its direction may destroy the stability of large dunes, thereby affecting sediment flux [85]. However, wind erosion processes are often random or strongly dependent on local environmental conditions, making them difficult to incorporate into general analyses or simulations of dune fields. Additionally, collisions between sand particles can adjust the dune shape and the distance between them. When sand particles collide with each other, sand will be redistributed between the dunes [86]. There is not yet a general theoretical model that can self-consistently explain this diversity of dune patterns.

In order to understand the mechanism of sand-particle collisions between sand dunes, it is necessary to use a continuum model for numerical simulations. Continuum dune models have been used to quantitatively connect dune characteristics to environmental conditions and physical processes, including interactions within a single sand dune and between multiple sand dunes. At larger scales, each sand dune is regarded as a single particle, and the results of the large-scale continuum model are used to explain the collisions between particles, i.e., interactions between sand dunes. The pioneering work of [87] is the basis of most sand dune formation and evolution continuum models. These models have been mainly applied to study the influences of wind and sand flux on details of dune morphology $[88,89]$, and the influence of vegetation and induration in stabilizing dunes [88]. Many studies have examined the characteristic scales of dune formation and evolution in different environments, such as underwater or on Mars [90,91]. Jump particles on the back of a windward dune hit the bottom of the dune, causing sand deposition, and ultimately remain in the windward dune. With the transport of windward dune sand, the dune's contour becomes shorter, which leads to a speed increase in the sand flux. Similarly, windward dunes accumulate sand, become taller, and thus reduce the sand flux speed [87]. It seems that the size ratio between dunes, not the individual size of dunes, determines the impact of sand collision on sediment transport [92-94].

In future studies, we will attempt to apply a continuum model to fields composed of hundreds of dunes. However, due to the large temporal and spatial scales involved and current technical constraints, its feasibility may be limited [87]. In other words, following the methods adopted in other research and the obtained basic parameters, we hope that the future measurements of sand flux in areas between desert sand dunes will help to develop better models for dune fields, based on previous agent-based simulations $[83,87,95]$. Such 
models rely on the accurate description of interdune sand transport, which is still poorly known, and should thus constitute a topic of further investigation in future work.

To sum up, in the complex field environment, differences in the horizontal dust fluxes and dust collection efficiencies were caused by differences in the type, accuracy, and sampling periods of the sand samplers, as well as the sand particle size and height. Therefore, in future research, developing a sand sampling device with a high sand collection efficiency that is sensitive to small disturbances to the flow fields in complicated fields is an important requirement to accurately estimate dust fluxes. Secondly, we aim to develop a numerical model, and then calibrate the model through field-measured data, so as to carry out numerical simulations of large-scale sediment flux and dust flux.

\section{Conclusions}

The cumulative collected sand mass and number of sand particles impacting the sensor of the designed sand sampler were highly consistent in the complex field test environment, which had a linear relationship with an $R^{2}$ value of 0.6053 , reflecting good performance in sand collection. The sand collection efficiency was about $94.3 \%$ for the sand sampler, indicating that the sand sampler could effectively monitor the movement of sand particles. The data obtained from field experiments allowed us to deduce a simple formula for calculating the dust horizontal flux: $F=256 \mathrm{M}$. We also estimated the maximum and minimum dust horizontal flux within a height of $5 \mathrm{~cm}$ near the surface of the mobile sand surface in the tower during 15 dust events, finding values of $190.335 \mathrm{~kg}$ and $1.2 \mathrm{~kg}$, respectively.

Based on the simultaneous observations of wind speed and temperature in our attempt to analyze the transitional sediment transport rate at a height of $5 \mathrm{~cm}$, it was found that with an increase of wind speed, the sediment transport rate generally increased, but during some weather periods, the sediment transport rate changed with the wind speed. Inconsistent, and in this case, the landmark temperature during the corresponding period is significantly higher.

Author Contributions: Conceptualization, X.L. and Y.K.; data curation, H.C.; formal analysis, H.L.; funding acquisition, H.C.; investigation, Y.K.; project administration, X.L.; software, Y.K.; supervision, H.L.; validation, H.C.; visualization, X.L.; writing—original draft, X.L.; writing—review and editing, Y.K. All authors have read and agreed to the published version of the manuscript.

Funding: This work was supported by the Tianshan Youth Talents (Xinjiang) Plan Project (2019Q037).

Institutional Review Board Statement: Not applicable for studies not involving humans.

Informed Consent Statement: Not applicable for studies not involving humans.

Data Availability Statement: Not applicable.

Conflicts of Interest: The authors declare no conflict of interest.

\section{References}

1. Anderson, R.S.; Haff, P.K. Simulation of eolian saltation. Science 1988, 241, 820-824. [CrossRef]

2. Kok, J.F.; Parteli, E.J.; Michaels, T.I.; Karam, D.B. The physics of wind-blown sand and dust. Rep. Prog. Phys. Physical Soc. 2012, 75, 106901. [CrossRef]

3. Shao, Y.P. Physics and Modelling of Wind Erosion; Kluwer Academic Publishers: Dordrecht, The Netherlands, 2008.

4. Ravi, S.; D’Odorico, P.; Breshears, D.D.; Field, J.P.; Goudie, A.; Huxman, T.E.; Li, J.; Okin, G.; Swap, R.; Thomas, A.; et al. Aeolian process and the biosphere. Rev. Geophys. 2011, 49, 45. [CrossRef]

5. Bullard, J.E.; Baddock, M.; Bradwell, T.; Crusius, J.; Darlington, E.; Gaiero, D.M.; Gassó, S.; Gisladottir, G.; Hodgkins, R.; McCulloch, R.; et al. High-latitude dust in the Earth system. Rev. Geophys. 2016, 54, 447-485. [CrossRef]

6. Jiang, F.; Ren, B.; Hursthouse, A.S.; Zhou, Y. Trace Metal Pollution in Topsoil Surrounding the Xiangtan Manganese Mine Area (South-Central China): Source Identification, Spatial Distribution and Assessment of Potential Ecological Risks. Int. J. Environ. Res. Public Health 2018, 15, 2412. [CrossRef]

7. Shao, Y.; Wyrwoll, K.H.; Chappell, A.; Huang, J. Dust cycle: An emerging core theme in earth system science. Aeolian Res. 2011, 2, 181-204. [CrossRef] 
8. Zou, X.; Zhang, C.; Cheng, H.; Kang, L.; Wu, Y. Cogitation on developing a dynamic model of soil wind erosion. Sci. China Earth Sci. 2015, 58, 462-473. [CrossRef]

9. Sharratt, B.S.; Mcguire, A.; Horneck, D. Early-season wind erosion influenced by soil-incorporated green manure in the Pacific Northwest. Soil Sci. Soc. Am. J. 2018, 82, 678-684. [CrossRef]

10. WHO. Air Quality Guidelines: Global Update 2005: Particulate Matter, Ozone, Nitrogen Dioxide, and Sulfur Dioxide; WHO: Geneva, Switzerland, 2006.

11. Li, J.; Shang, J.; Huang, D.; Tang, S.; Zhao, T.; Yang, X.; Zhang, Q.; Liu, K.; Shao, X. Grazing and Cultivated Grasslands Cause Different Spatial Redistributions of Soil Particles. Int. J. Environ. Res. Public Health 2019, 16, 2639. [CrossRef]

12. Zhang, S.; Ding, G.-D.; Yu, M.-H.; Gao, G.-L.; Zhao, Y.-Y.; Wu, G.-H.; Wang, L. Effect of Straw Checkerboards on Wind Proofing, Sand Fixation, and Ecological Restoration in Shifting Sandy Land. Int. J. Environ. Res. Public Health 2018, 15, 2184. [CrossRef]

13. Peri, P.L.; Bloomberg, M. Wind breaks in southern Patagonia, Argentina: A review of research on growth models, windspeed reduction, and effects oncrops. Agrofor. Syst. 2002, 56, 129-144. [CrossRef]

14. Wang, L.-Y.; Xiao, Y.; Rao, E.-M.; Jiang, L.; Xiao, Y.; Ouyang, Z.-Y. An Assessment of the Impact of Urbanization on Soil Erosion in Inner Mongolia. Int. J. Environ. Res. Public Health 2018, 15, 550. [CrossRef]

15. Alemu, M.M. Ecological benefits of trees as wind breaks and shelter belts. Phys. Geogr. 2016, 6, 10-13.

16. Tshehla, C.E.; Wright, C.Y. Spatial and Temporal Variation of PM10 from Industrial Point Sources in a Rural Area in Limpopo, South Africa. Int. J. Environ. Res. Public Health 2019, 16, 3455. [CrossRef] [PubMed]

17. Nickling, W.G.; McKenna Neuman, C. Wind tunnel evaluation of a wedgeshaped aeolian sediment trap. Geomorphology 1997, 18, 333-345. [CrossRef]

18. Ono, D.; Weaver, S.; Richmond, K. Quantifying Particulate Matter Emissions from Wind Blown Dust using Real-Time Sand Flux Measurements; Owens Emissions Papers, Paper-C; EPA: Washington, DC, USA, 2003.

19. Zobeck, T.M.; Sterk, G.; Funk, R.; Rajot, J.L.; Stout, J.E.; Van Pelt, R.S. Measurement and data analysis methods for field-scale wind erosion studies and model validation. Earth Surf. Proc. Land. 2003, 28, 1163-1188. [CrossRef]

20. Van Pelt, R.S.; Peters, P.; Visser, S. Laboratory wind tunnel testing of three com-monly used saltation impact sensors. Aeolian Res. 2009, 1, 55-62. [CrossRef]

21. Webb, N.P.; Herrick, J.E.; Van Zee, J.W. The national wind erosion research network: Building astandardized long-term data resource for aeolian research, modeling and land man-agement. Aeolian Res. 2016, 22, 23-36. [CrossRef]

22. Goossens, D.; Nolet, C.; Etyemezian, V. Field testing, comparison, and discussion of five aeolian sand transport measuring devices operating on different measuring principles. Aeolian Res. 2018, 32, 1-13. [CrossRef]

23. Leatherman, S.P. Short communication: A new aeolian sand trap design. Sedimentology 1978, 25, 303-306. [CrossRef]

24. Fryberger, S.G.; Al-Sari, A.M.; Clisham, T.J. Wind sedimentation in the Jafurah sand sea, Saudi Arabia. Sedimentology 1984, 31, 413-431. [CrossRef]

25. Zhong, H.Y.; Lin, C.; Sun, Y.; Kikumoto, H.; Ooka, R.; Zhang, H.L.; Hu, H.; Zhao, F.Y.; Jimenez-Bescos, C. Boundary layer wind tunnel modeling experiments on pumping ventilation through a three-story reduce-scaled building with two openings. Build. Environ. 2021, 202, 108043. [CrossRef]

26. Wang, R.D.; Li, Q.; Chang, C.P.; Guo, Z.L. Sampling efficiency of a new flat opening collector for particles with various sizes. J. Des. Res. 2018, 38, 734 .

27. Wilson, S.J.; Cooke, R.U. Wind erosion. In Soil Erosion; Kirkby, M.J., Morgan, R.P.C., Eds.; Wiley: Chichester, UK, 1980; pp. 217-252.

28. Fryrear, D.W. A field dust sampler. J. Soil Water Conserv. 1986, 41, 117-120.

29. Dong, Z.; Sun, H.; Zhao, A. WITSEG sampler: A segmented sand sampler for wind tunnel test. Geomorphology 2004, 59, 119-129. [CrossRef]

30. Zhao, Y.L.; Ma, S.S.; Chen, Z.; Sun, Y.C. The calibration of the whirl type separation sand sampler. J. Agr. Mech. Res. 2007, 4, 95-98.

31. Gu, Z.; Guo, L. Experimental investigation on trap stagnant effect and sand flux in aeolian sand transport. Phys. Lett. A 2007, 368, 435-441. [CrossRef]

32. Basaran, M.; Erpul, G.; Uzun, O.; Gabriels, D. Comparative efficiency testing for a newly designed cyclone type sediment trap for wind erosion measurements. Geomorphol. 2011, 130, 343-351. [CrossRef]

33. Rotnicka, J. Aeolian vertical mass flux profiles above dry and moist sandy beach surfaces. Geomorphol. 2013, 187, 27-37. [CrossRef]

34. Sherman, D.; Swann, C.; Barron, J. A high-efficiency, low-cost aeolian sand trap. Aeolian Res. 2014, 13, 31-34. [CrossRef]

35. Hilton, M.; Nickling, B.; Wakes, S.; Sherman, D.; Konlechner, T.; Jermy, M.; Geoghegan, P. An efficient, self-orienting, vertical-array, sand trap. Aeolian Res. 2017, 25, 11-21. [CrossRef]

36. Goossens, D.; Offer, Z.; London, G. Wind tunnel and field calibration of five aeolian sand traps. Geomorphology 2000, 35, 233-252. [CrossRef]

37. Kang, Y.; He, Q.; Yang, X. Based on the earth's surface layer dust flux field observation and study on collection efficiency. Am. J. Med. Sci. Med. 2017, 5. [CrossRef]

38. An, M.; Li, S.; Liu, Z.; Yan, B.; Li, L.; Chen, Z. Galloping vibration of stay cable installed with a rectangular lamp: Field observations and wind tunnel tests. J. Wind. Eng. Ind. Aerodyn. 2021, 215, 104685.

39. Shannak, B.; Corsmeier, U.; Kottmeier, C.; Al-Azab, T. Wind tunnel study of twelve dust samples by large particle size. Atmos. Environ. 2014, 98, 442-453. [CrossRef] 
40. Martin, R.L.; Kok, J.F. Size-independent susceptibility to transport in aeolian saltation. J. Geophys. Res. Earth Surf. 2019, 124, 1658-1674. [CrossRef]

41. Namikas, S.L. Field evaluation of two traps for high-resolution aeolian transport measurements. J. Coast. Res. 2002, 18, 136-148.

42. Haustein, K.; Washington, R.; King, J. Testing the performance of state-of-the-art dust emission schemes using DO4Models field data. Geosci. Model Dev. 2015, 8, 341-362. [CrossRef]

43. Li, Z.S.; Ni, J.R. Sampling efficiency of vertical array aeolian sand traps. Geomorphology 2003, 52, 243-252. [CrossRef]

44. Lin, Y.; Hang, J.; Yang, H.; Chen, L.; Chen, G.; Ling, H.; Sandberg, M.; Claesson, L.; Lam, C.K.C. Investigation of the Reynolds number independence of cavity flow in 2D street canyons by wind tunnel experiments and numerical simulations. Build. Environ. 2021, 201, 107965. [CrossRef]

45. Zhao, C.M. Analysis of Sand Grain Morphology in Taklimakan Desert; Xinjiang Normal University: Urumqi, China, 2012; (In Chinese with English Abstract).

46. He, Q.; Yang, X.H. Study on wind-induced sand observations in Taklimakan Desert-Preliminary study of test and observation results. J. China Desert 2011, 31, 56-61, (In Chinese with English Abstract).

47. Yang, X.H.; He, Q. A field experiment on dust emission by wind erosion in the Taklimakan desert. Acta Meteor, Sinica 2012, 26, 241-249. [CrossRef]

48. Kang, Y.; He, Q. Urumqi. J. Arid Land Resour. Environ. 2017, 31, 119-125, (In Chinese with English Abstract).

49. Xu, J.; Xiao, Y.; Xie, G.; Zhen, L.; Wang, Y.; Jiang, Y. The spatio-temporal disparities of areas benefitting from the wind erosion prevention service. Int. J. Environ. Res. Public Health 2018, 15, 1510. [CrossRef]

50. Anderson, R.S.; Haff, P.K. Wind modification and bed response during saltation of sand in air. Acta Mech. Suppl. 1991, 1, 21-51.

51. McEwan, I.K.; Willetts, B.B. Adaptation of the near-surface wind to the development of sand transport. J. Fluid Mech. 1993, 252, 99-115. [CrossRef]

52. Ungar, J.E.; Haff, P.K. Steady-state saltation in air. Sedimentology 1987, 34, 289-299. [CrossRef]

53. Ma, G.; Wang, Y.; Zheng, J. Numerical analysis of the influence of the near ground turbulence on the wind-sand flow under the natural wind. Granular Matter 2021, 23, 40. [CrossRef]

54. Huang, N.; He, P.; Zhang, J. Large-eddy simulation of sand transport under unsteady wind. Geomorphol. 2020, $358,107105$. [CrossRef]

55. Shao, Y.; Raupach, M.R. The overshoot and equilibration of saltation. J. Geophys. Res. 1992, 97, 20559-20564. [CrossRef]

56. Rice, M.A.; Willetts, B.B.; McEwan, I.K. An experimental study of multiple grain-size ejecta produced by collisions of saltating grains with a flat bed. Sedimentology 1995, 42, 695-706. [CrossRef]

57. Kok, J.F.; Renno, N.O. A comprehensive numerical model of steady state saltation (COMSALT). J. Geophys. Res. 2009, 114, D17204. [CrossRef]

58. Gillette, D.A. On the production of soil wind erosion having the potential for long range transport. J. Rech. Atmos. 1974, 8, 734-744.

59. Shao, Y.; Raupach, M.R.; Findlater, P.A. Effect of saltation bombardment on the entrainment of dust by wind. J. Geophys. Res. 1993, 98, 12719-12726. [CrossRef]

60. Dur'an, O.; Claudin, P.; Andreotti, B. On aeolian transport: Grain-scale interactions, dynamical mechanisms and scaling laws. Aeolian Res. 2011, 3, 243-270. [CrossRef]

61. Bagnold, R.A. The movement of desert sand Proc. R. Soc. Lond. A 157 0594-620 Owen P R 1964 Saltation of uniform grains in air. J. Fluid Mech. 1936, 20, 225-242.

62. Owen, P.R. Saltation of uniform grains in air. J. Fluid Mech. 1964, 20, 225-242. [CrossRef]

63. Sorensen, M.; McEwan, I. On the effect of mid-air collisions on aeolian saltation. Sedimentology 1996, 43, 65-76. [CrossRef]

64. Dong, Z.; Liu, X.; Li, F.; Wang, H.; Zhao, A. Impact-entrainment relationship in a saltating cloud. Earth Surf. Process. Landf. 2002, 27, 641-658. [CrossRef]

65. Dong, Z.B.; Huang, N.; Liu, X.P. Simul of the probability of midair interparticle collisions in an aeolian saltating cloud. J. Geophys. Res. 2005, 110, D24113. [CrossRef]

66. Huang, N.; Zhang, Y.L.; D'Adamo, R. A model of the trajectories and midair collision probabilities of sand particles in a steady state saltation cloud. J. Geophys. Res. 2007, 112, D08206. [CrossRef]

67. Rice, M.A.; Willetts, B.B.; McEwan, I.K. Observations of collisions of saltating grains with a granular bed from high-speed cine-film. Sedimentology 1996, 43, 21-31. [CrossRef]

68. Gordon, M.; Neuman, C.M. A comparison of collisions of saltating grains with loose and consolidated silt surfaces. J. Geophys. Res. 2009, 114, F04015. [CrossRef]

69. Oger, L.; Ammi, M.; Valance, A. Discrete Element Method studies of the collision of one rapid sphere on 2D and 3D packings. Eur. Phys. J. E 2005, 17, 467-476. [CrossRef]

70. Oger, L.; Ammi, M.; Valance, A. Study of the collision of one rapid sphere on 3D packings: Experimental and numerical results. Comput. Math. Appl. 2008, 55, 132-148. [CrossRef]

71. Werner. B.T. A steady-state model of wind-blown sand transport. J. Geol. 1990, 98, 1-17.

72. Mitha, S.; Tran, M.Q.; Werner, B.T. The grain-bed impact process in aeolian saltation. Acta Mech. 1986, 63, 267-278. [CrossRef]

73. Ho, T.D.; Dupont, P.; El Moctar, A.O.; Valance, A. 2012 Particle velocity distribution in saltation transport. Phys. Rev. E 2012, 85, 052301. [CrossRef] [PubMed] 
74. Fu, G.; Xu, X.; Qiu, X.; Xu, G.; Shang, W.; Yang, X.; Zhao, P.; Chai, C.; Hu, X.; Zhang, Y.; et al. Wind tunnel study of the effect of planting Haloxylon ammodendron on aeolian sediment transport. Biosyst. Eng. 2021, 208, 234-245. [CrossRef]

75. Baas, A.C.W. Evaluation of saltation flux impact responders (Safires) for measuring instantaneous aeolian sand transport intensity. Geomorphology 2004, 59, 99-118. [CrossRef]

76. McKee, E.D. A Study of Global Sand Seas; US Government Printing Office: Washington, DC, USA, 1979.

77. Dong, Z.B.; Man, D.Q.; Luo, W.Y. Horizontal aeolian sediment flux in the Minqin area, a major source of Chinese dust storms. Geomorphology 2010, 116, 58-66. [CrossRef]

78. Sharratt, B. Size distribution of windblown sediment emitted from agricultural fields in the Columbia Plateau. Soil Sci. Soc. Am. J. 2011, 75, 1054-1060. [CrossRef]

79. Farrell, E.J.; Sherman, D.J. Vertical distribution of grain size for wind blown sand. Aeolian Res. 2012, 7, 51-61. [CrossRef]

80. Zhang, Z.C.; Dong, Z.B.; Zhao, A.G. The characteristics of aeolian sediment flux profiles in the south-eastern Tengger Desert. Sedimentology 2011, 58, 1884-1894. [CrossRef]

81. Pierre, C.; Bergametti, G.; Marticorena, B. Modeling wind erosion flux and its seasonality from a cultivated sahelian surface: A case study in Niger. Catena 2014, 122, 61-71. [CrossRef]

82. Zhang, Z.C.; Dong, Z.B.; Qian, G.Q. An investigation into the pro-cesses and quantity of dust emissions over gravel and sand deserts in north-western China. Bound. Layer Meteorol. 2017, 163, 523-535. [CrossRef]

83. EParteli, J.R.; Herrmann, H.J. A simple model for a transverse dune field. Physica A 2003, 327, 554-562. [CrossRef]

84. Hersen, P.; Andersen, K.H.; Elbelrhiti, H.; Andreotti, B.; Claudin, P.; Douady, S. Corridors of barchan dunes: Stability and size selection. Phys. Rev. E 2004, 69, 011304. [CrossRef] [PubMed]

85. Elbelrhiti, H.; Claudin, P.; Andreotti, B. Field evidence for surface-wave-induced instability of sand dunes. Nature 2005, 437, 720-723. [CrossRef]

86. Hersen, P.; Douady, S. Collision of barchan dunes as a mechanism of size regulation. Geophys. Res. Lett. 2005, 32, 21403. [CrossRef]

87. Diniega, S.; Glasner, K.; Byrne, S. Long-time evolution of models of aeolian sand dune fields: Influence of dune formation and collision. Geomorphol. 2010, 121, 55-68. [CrossRef]

88. Herrmann, H.J.; Durán, O.; Parteli, E.J.R.; Schatz, V. Vegetation and Induration as Sand Dunes Stabilizators. J. Coast. Res. 2008, 246, 1357-1368. [CrossRef]

89. Parteli, E.J.R.; Durán, O.; Herrmann, H.J. The shape of the barchan dunes in the Arkhangelsky Crater on Mars. In Proceedings of the 37th Annual Lunar and Planetary Science Conference, League City, TX, USA, 13-17 March 2006.

90. Claudin, P.; Andreotti, B. A scaling law for aeolian dunes on Mars, Venus, Earth, and for subaqueous ripples. Earth Planet. Sci. Lett. 2006, 252, 30-44. [CrossRef]

91. Parteli, E.J.R.; Herrmann, H.J. Dune formation on the present Mars. Phys. Rev. E 2007, 76, 041307. [CrossRef] [PubMed]

92. Katsuki, A.; Nishimori, H.; Endo, N.; Taniguchi, K. Collision Dynamics of Two Barchan Dunes Simulated Using a Simple Model. J. Phys. Soc. Jpn. 2005, 74, 538-541. [CrossRef]

93. Endo, N.; Taniguchi, K.; Katsuki, A. Observation of the whole process of interaction between barchans by flume experiments. Geophys. Res. Lett. 2004, 31, 12503. [CrossRef]

94. Durán, O.; Schwämmle, V.; Herrmann, H. Breeding and solitary wave behavior of dunes. Phys. Rev. E 2005, 72, 021308. [CrossRef]

95. Génois, M.; Du Pont, S.C.; Hersen, P.; Grégoire, G. An agent based model of dune interactions produces the emergence of patterns in deserts. Geophys. Res. Lett. 2013, 40, 3909-3914. [CrossRef] 